\title{
Dynamic Lidar Ratio Calculation and Aerosol Vertical Extinction Coefficient Retrieval Based on Observed Visibility
}

\author{
Chuanli Du ${ }^{1,2^{*}}$, Ziyan Guo ${ }^{3}$, Shuyan Liư ${ }^{4}$ Xingmin $\mathrm{Li}^{1,2}$, Zipeng Dong ${ }^{1,2}$, \\ Yan Dong ${ }^{1,2}$, Yan Peng ${ }^{1,2}$, Ying $\mathbf{X i}^{1,2}$ \\ ${ }^{1}$ Meteorological Institute of Shaanxi Province, Xi'an 710015, China \\ ${ }^{2}$ Key Laboratory of Eco-Environment and Meteorology for the Qinling Mountains and Loess \\ Plateau, Xi'an 710015, China \\ ${ }^{3}$ Institute of Meteorology and Climate Research, Karlsruhe Institute of Technology, 76131 \\ Karlsruhe, Germay \\ ${ }^{4}$ Cooperative Institute for Research in the Atmosphere, Colorado State University, CO 80521, \\ USA
}

\section{ABSTRACT}

Micropulse lidar (MPL) cannot directly retrieve the aerosol extinction coefficient under cloudy conditions and at night. Therefore, we used ground visibility, Fernald's near-end solution method, and the linear correlation between the near-end lidar signal (photons) and ground aerosol extinction coefficient (correlation coefficient $=0.98$ ), to calculate the lidar constant and lidar ratio $(\mathrm{LR})$. We compared the aerosol optical depth (AOD) retrieved from MPL and the AOD retrieved from the multifilter rotating shadowband radiometer (MFRSR-7) at the same band (532 nm). The correlation coefficient was 0.77 . The vertical distribution of aerosols in daytime and nighttime during summer was obtained from lidar in July at 00:00 and 12:00 Beijing time (UTC+8). In daytime, under clear sky conditions, the distribution displayed a unimodal and peak at approximately $2000 \mathrm{~m}$. The distribution at night was more complicated than that in the day, with three results. The first was monotonically decreasing from ground to upper layer, with a peak at $600 \mathrm{~m}$ and two peaks at approximately $1200 \mathrm{~m}$. In general, the aerosol extinction coefficient at nighttime is higher than that at daytime below $1200 \mathrm{~m}$. The near-ground extinction coefficient at night is higher than in the day.

Received: December 11, 2020 Revised: November 2, 2021

Accepted: November 3, 2021

${ }^{*}$ Corresponding Author:

duchuanli@foxmail.com

\section{Publisher:}

Taiwan Association for Aerosol Research

ISSN: $1680-8584$ print

ISSN: 2071-1409 online

Copyright: The Author(s). This is an open access article distributed under the terms of the Creative Commons Attribution License (CC BY 4.0), which permits unrestricted use, distribution, and reproduction in any medium, provided the original author and source are cited.
Keywords: Micropulse lidar, Dynamic lidar ratio, Visibility, AOD, Extinction coefficient

\section{INTRODUCTION}

Aerosol vertical distribution characteristics have critical effects on both weather and climate. The variety in distributions can lead to difficulties in numerous fields of studies, such as microphysics, satellite meteorology, and air quality research. Aerosol vertical distribution can also be affected by clouds and precipitation as well as solar radiation scattering and absorption. Therefore, highresolution detection of the atmospheric aerosol extinction coefficient is crucial in global climate change or regional extreme weather event research (Schuster et al., 2012; Srivastava et al., 2012).

As laser technology develops, laser detection methods are becoming increasingly crucial in the field of atmospheric sounding (Chen et al., 2010; Spinhime, 1993; Zhou et al., 1998). Methods to retrieve aerosol optical characteristics have been presented by Collis and Russell (1976), Klett (1981), and Fernald (1984). Fernald's lidar equation for the near-end solution method is commonly used. Using the Fernald method to solve the lidar equation requires three input parameters: the lidar constant (CE), extinction-to-backscatter ratio (also known as lidar ratio [LR], unit: sr), and boundary values. We determined the boundary values by selecting a calibration point at the height with the minimum aerosol content near the tropopause. Assuming that LR is constant at 
this point, the aerosol vertical extinction coefficient can be calculated. The lidar effective detection range cannot always reach tropopause because this method is limited by its detection capability and cloud interference. Therefore, the selection of the calibration height and appropriate boundary value is critical for accurate retrieval (Liu et al., 2008). A constant value is always used for LR, which affects retrieval. Although the wavelength is $532 \mathrm{~nm}$, the LR for urban aerosol is $50 \mathrm{sr}$, the LR for dust aerosol in Asia is 40-60 sr, and the LR for marine aerosol is approximately $20 \mathrm{sr}$ (Wang and Rao, 2005). The wide range of observed LR indicates that assigning $L R$ a constant value in retrieval is not very accurate. A study indicated that $L R$ biases affect aerosol extinction coefficient accuracy, particularly when the aerosol has various vertical distributions (Doherty et al., 1999).

To retrieve the aerosol extinction coefficient under different topographical and meteorological conditions, accurate corresponding values of LR are required. Methods to obtain LR can be divided into two categories: independent measurement and joint retrieval. The independent measurement methods include multiangle measurement (Spinhirne, 1993), high spectral resolution lidar measurement, and Raman lidar measurement (Otto et al., 2009). Joint LR retrieval methods include vertical integration methods that use satellite observed optical thickness to restrain the lidar observed aerosol extinction coefficient and solar photometer combined with lidar to retrieve LR (Pietruczuk and Podgórski, 2009).

However, joint retrieval methods have limitations. Satellite and solar photometers cannot retrievethe aerosol optical depth (AOD) under cloudy sky conditions or at night (Lunar measurement of $A O D$ can be performed at night now). The lidar effective detection height cannot reach tropopause because of the instrument limitations and cloud effects. Therefore, determining the boundary value and reasonable calibration is crucial for accurate retrieval (Liu et al., 2008). To solve this problem, we calculated LR dynamically using ground visibility according to linear relationship between the near-end lidar signal (photons) and aerosol extinction coefficient (Lin et al., 2013). This method can be used to retrieve the lidar aerosol vertical extinction coefficient under any sky conditions.

\section{INSTRUMENT AND OBSERVATION}

\subsection{Micropulse Lidar}

The micropulse lidar (MPL) is installed on the top of a container, placed $3 \mathrm{~m}$ above ground at the atmospheric science experimental base at Qinling, Shaanxi Province, China $\left(108^{\circ} 55^{\prime} \mathrm{N}, 34^{\circ} 09^{\prime} \mathrm{E}\right)$. Observations have been continually recorded from 25 October 2012 to the present. Days without missing values from the summer of 2016 were selected for this study. The lidar is MPL-4B-532 MPL, including a laser, coaxial optics, and a control cabinet. It is provided by Droplet Measurement Technologies (USA). Table 1 lists the instruments and parameters. The data sampling temporal interval is set at $100 \mathrm{~ns}$, corresponding to a vertical resolution of $30 \mathrm{~m}$. The average data recording time is $30 \mathrm{~s}$. Lidar sampling interval and average data recording time determine the lidar's temporal and spatial resolution and affect the signal-to-noise ratio (SNR) (Li et al., 2004). Lidar output data is the received photon number, which is normalized to backscattering signal after

Table 1. The MPL system and its technical parameters.

\begin{tabular}{lll}
\hline Instrument & Parameter & \\
\hline Laser Transmitter & Wavelength & $532 \mathrm{~nm}$ \\
& Pulse Energy & $6-8 \mu \mathrm{J}$ \\
& Frequency & $2500 \mathrm{~Hz}$ \\
Receiver & Width & $20 \mathrm{~nm}$ \\
& Telescope Type & Cassegrain Telescope \\
& Diameter & $178 \mathrm{~mm}$ \\
Detector & Field of View & $90 \mu \mathrm{rad}$ \\
& Focal Length & $2400 \mathrm{~mm}$ \\
& Detector & Photon Counter \\
& resolution & $30 \mathrm{~m}$ \\
& maximum detection ehight & $30 \mathrm{~km}$ \\
\hline
\end{tabular}


background correction, overlap correction, and range correction (Campbell et al., 2002). The aerosol extinction coefficient vertical distribution can then be retrieved from the single scattering lidar equation.

The Qinling atmospheric science experimental base in Shaanxi Province was one of the field observational bases certified by the China Meteorological Administration in 2018. The field observational base operates multiple instruments to observe the optical and physical properties of atmospheric aerosol, including an Aerodynamic Particle Sizer spectrometer, scanning mobility particle sizer spectrometer, three-band particle soot/absorption photometer, total sky imager, integrating nephelometer, and various ground radiometers. Other observational instruments were also available, such as the boundary layer wind profiler, microwave radiometer, atmospheric composition observatory ( $\mathrm{PM}_{2.5}, \mathrm{PM}_{10}, \mathrm{CO}$, nitrogen oxides, and sulfide) of Xi'an Environmental Protection Station, and ground meteorology observations (visibility, relative humidity, wind speed and direction, precipitation, etc.).

\subsection{Foreword Scattering Visibility Meter}

The foreword scattering visibility meter (FSVM) is HY-V35, which it is provided by Huayun Sounding (Beijing) Meteorological Technology Corporation (Huayun Sounding). The forward scattering visibility meter is an instrument that estimates the optical range by measuring the scattering coefficient of light pulse. The optical range refers to the path length through which the luminous flux of the parallel beam emitted by the incandescent lamp with a color temperature of $2700 \mathrm{k}$ reduces to $5 \%$ of the initial value in the atmosphere.

Xue (2016) analyzed the observed visibility by the HY-V35 visibility-meter and the manually observed value. In the clear sky, the observed visibility has the slightest difference from the manually observed value, which is only $3 \%$; In the case of light fog/haze and precipitation, the difference between the two is $30 \%$ and $24 \%$, respectively, and HY-V35 observed value is significantly less than manually observed. Li (2009) deduced the detection equation of the visibility meter based on the measurement principle and scattering theory. On this basis, the visibility uncertainty was analyzed by the combination of simulation calculation and statistical analysis. The results show that the relative uncertainty of visibility caused by performance uncertainty is only $4 \%$ under the current technological conditions. The main error sources of HY-V35 are scattering phase function changes caused by aerosol properties. Because of the uncertainty of aerosol properties, the relative uncertainty of HY-V35 reaches $28 \%$. When the atmospheric aerosols are fog, rural aerosol, and urban aerosol, the relative uncertainties are $7 \%, 9 \%$, and $18 \%$, respectively, under some specific conditions.

Obviously, under fog/haze and rainy weather conditions, the error of HY-V35 is relatively large. To reduce the uncertainty of HY-V35, the time when the visibility is less than $2 \mathrm{~km}$ is eliminated in the calculation process. In this way, visibility data were used to calculate the LR by linear regression and then calculate the ground aerosol extinction coefficient.

\subsection{Multifilter Rotating Shadowband Radiometer}

The multifilter rotating shadowband radiometer 7 (MFRSR-7) is installed in the same container as the lidar at the aforementioned experimental base. The observation time was from October 2012 to the present. The MFRSR-7 measured the total horizontal radiation and diffuse radiation at seven bands, among which six had a narrow bandwidth of $10 \mathrm{~nm}$. The six bands comprised four visible bands with center wavelengths of 414.3, 495.3, 613.7, and $867.6 \mathrm{~nm}$ and two infrared bands with center wavelengths of 867.6 and $939.3 \mathrm{~nm}$. Different bands were used to retrieve aerosol, cloud, and water vapor. The other bands within a wavelength range of 300-1100 nm, which were sensitive to silicon material, were used to observe solar total radiation. The AOD retrieved by MFRSR-7 at $532 \mathrm{~nm}$ was used as independent data to test lidar retrieved AOD.

\section{RETRIEVAL ALGORITHM}

\subsection{Calculation of Near-end Normalized Relative Backscatter (NRB)}

According to the lidar equation (Lin et al., 2013), the normalized near-end backscattering signal can be calculated as follows: 
$X\left(z_{0}\right)=C E\left(\beta_{a}\left(z_{0}\right)+\beta_{m}\left(z_{0}\right)\right)=\frac{C E}{S_{a}} \alpha_{a}\left(z_{0}\right)+C E \beta_{m}\left(z_{0}\right)$

where $C E$ and $S_{a}$ can be retrieved based on the near-end lidar signal (photons) and ground aerosol extinction coefficient, $\mathrm{CE} / S_{a}$ is the slope, $\mathrm{Ce} \beta_{m}\left(z_{0}\right)$ is the intercept, $X\left(z_{0}\right)$ is the near-end lidar signal (photons), $\alpha_{a}\left(z_{0}\right)$ is the ground aerosol extinction coefficient, $\beta_{m}\left(z_{0}\right)$ is the ground atmospheric molecule backscattering coefficient (calculated with temperature and air pressure at different heights using the empirical formula), and $S_{a}$ is the LR.

\subsection{Calculation of Ground Aerosol Extinction Coefficient}

The conversion between visibility and extinction coefficient can be performed using the following equation (Yao et al., 2010):

$\alpha=2.996 / V_{R}$,

where 2.996 is the Koschmeider constant, recommended by the World Meteorological Organization. We assumed that the target is a dark and ideal object, the contrast threshold is 0.05 , the atmosphere between the target and observer is ideal, the earth's curvature is negligible, and the brightness was homogenous. Furthermore, the atmospheric extinction coefficient can be calculated as follows:

$\alpha=\alpha_{a}+\alpha_{m}$

where $\alpha_{a}$ and $\alpha_{m}$ are the extinction coefficients for aerosol and standard atmospheric molecule, respectively; $\alpha_{m}$ can be calculated using an empirical formula:

$\alpha_{m}=9.807 \times 10^{-23} \times 273 /(273+\mathrm{T}) \times \mathrm{P} / 1013 \times\left(1 /\left(532 \times 10^{-7}\right)^{4.0117}\right.$,

where $\mathrm{T}$ and $\mathrm{P}$ represent the temperature and pressure at different heights, respectively.

$\beta_{m}$ is the ground atmospheric backscattering coefficient, which can be therefore calculated as:

$\beta_{m}=\alpha_{m} \times 3 /(8 \pi)$

Therefore, the ground aerosol extinction coefficient $\alpha_{a}\left(z_{0}\right)$ can be then calculated as follows:

$\alpha_{a}\left(z_{0}\right)=\alpha\left(z_{0}\right)-\alpha_{m}\left(z_{0}\right)$

\subsection{Calculation of Dynamic LR from Ground Visibility}

According to Eq. (1), the normalized near-end backscattering signal and ground extinction coefficient display a linear relationship when the CE and LR values are fixed, which can be expressed using the following equation:

$X\left(z_{0}\right)=a x+b$

Furthermore, $a$ and $b$ can be calculated using the lidar equation:

$a=C E / S_{a} \quad b=C E \beta_{m}\left(z_{0}\right)$

We assumed that the aerosol extinction coefficient does not change in the lidar blind zone $(270 \mathrm{~m})$; therefore, $X\left(z_{m}\right)$ and $X\left(z_{0}\right)$ are normalized backscattering coefficients at lidar's minimum effective height, $Z_{m}$, and at the ground, respectively. The relationship between $X\left(z_{m}\right)$ and $X\left(z_{0}\right)$ can be expressed as follow (Lin et al., 2013): 


$$
\begin{aligned}
X\left(z_{m}\right) & =C E\left(\beta_{a}\left(z_{m}\right)+\beta_{m}\left(z_{m}\right)\right) \cdot \exp \left\{-2 \int_{0}^{z_{m}}\left(\sigma_{a}(z)+\sigma_{m}(z)\right) d z\right\} \\
& =X\left(z_{0}\right) \exp \left\{-2 \int_{0}^{z_{m}}\left(\sigma_{a}\left(z_{0}\right)+\sigma_{m}(z) d z\right)\right\}
\end{aligned}
$$

During daytime observation, the ground aerosol extinction coefficient does not change considerably. This equation is thus not suitable in this situation. Herein, we assume that aerosol content does not change over 7 days, and we calculated the CE and LR with all lidar observation data during this period. The CE and LR were then calculated over the next time steps until all data were processed. To reduce the biases caused by the constant aerosol extinction coefficient assumed in the lidar blind zone $(270 \mathrm{~m})$, we only selected data during daytime between 10:0018:00 (UTC+8) to calculate. Because of the solar radiation effect, atmospheric convection at daytime is more frequent than at nighttime, which results in increased mixing of aerosols in the boundary layer, thereby reducing the difference in aerosol extinction coefficient in the lidar blind zone.

As shown in Fig. 1, This study used visibility and lidar echo data at the minute temporal interval for matching and calculating because the hourly data had too few valid points. The local aerosol content was assumed not to vary much over a short period, so LR remains constant during the period. The match-up period was set at a week ( 7 days) from 10:00 to 18:00 local time. All of the lidar NRB and visibility minute data during the period were included to calculate the near-end lidar signal (photons) and ground extinction coefficient. The points with $X\left(z_{0}\right)<1000$ and visibility $<1 \mathrm{~km}$ were filtered out to prevent calculation errors. We determined that MPL overestimated AOD when the lidar's SNR was too small. Therefore, the retrieval was performed for data with SNR $>30$ and start from the height of the lidar blind zone $(270 \mathrm{~m})$. The data with $\mathrm{SNR}<30$ were filtered out.

\section{RESULTS AND VALIDATION}

\subsection{Calculation of Dynamic LR}

A scatter plot of all the matched the near-end lidar signal (photons) and ground aerosol extinction

Flow Chart of Aerosol Vertical Extinction Coefficient Inversion

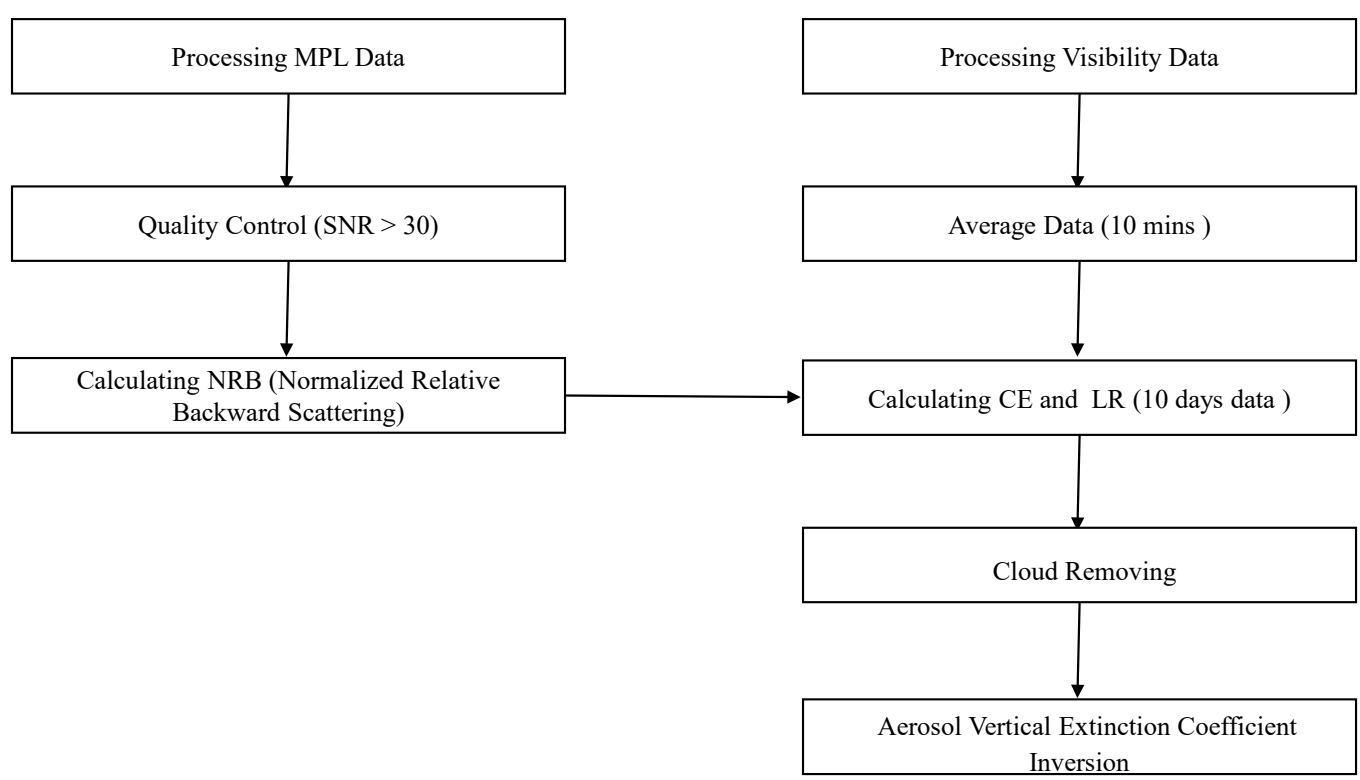

Fig. 1. Flow chart of aerosol vertical extinction coefficient inversion. 


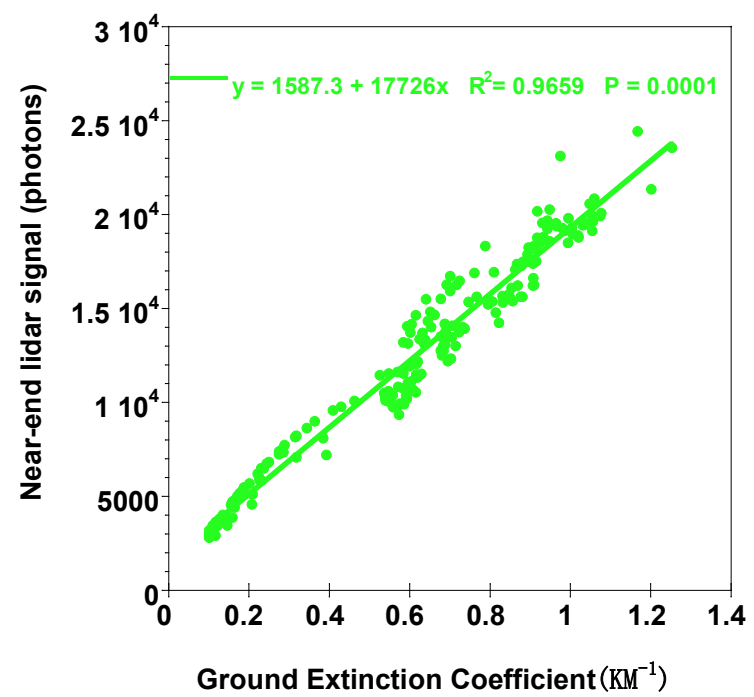

Fig. 2. Scatter plots between near-end lidar signal (photons) and ground extinction coefficient $\left(\mathrm{km}^{-1}\right)$.

coefficients is presented in Fig. 2 . The two variables were highly correlated $\left(R^{2}=0.9659, P=\right.$ 0.0001). Based on the intercept and slope of the linear fitting function and Eq. (6), the CE and LR were calculated using 684,181 and 38 sr values. The CE changed little with attenuated laser emitted energy. Therefore, we focused on the calculated dynamic LR.

Fernald's lidar equation near the end solution to retrieve aerosol vertical extinction coefficient has two unknown parameters, the boundary value and LR. The boundary value can be determined by assuming that the aerosol vertical distribution is uniform within the lidar blind zone and calculating the ground aerosol extinction coefficient. The LR can be calculated using a linear regression function based on the near-end lidar signal (photons) and ground extinction coefficient. Using a fixed LR to retrieve a long series of lidar echo data is not very accurate because it causes large biases for retrieved aerosol vertical extinction coefficient. Therefore, we used dynamic LR to process the lidar data. Visibility at the minute resolution was used to calculate and update LR every hour to process lidar data. Fernald's lidar equation for near-end solution was then solved using the ground aerosol extinction coefficient and the boundary value. Then, the aerosol vertical extinction coefficient was retrieved.

The lidar ratio not only depends on aerosol type (especially aerosol size and virtual refractive index), but also depends on relative humidity (Omar et al., 2010). Fig. 3 presents the time series of $L R$, calculated from the ground visibility and relative humidity in July 2016. Large variations in LR were observed, with a maximum value of $58.23 \mathrm{sr}$, a minimum value of $39.97 \mathrm{sr}$, and a mean value of $51.33 \mathrm{sr}$. These results were consistent with reports that LR ranges from 40 to $80 \mathrm{sr}$ for continental aerosol (Ackermann, 1998). LR is also affected by the relative humidity. Comparison with relative humidity time series indicated that $L R$ and relative humidity variations were correlated from 1 July to 19 July, After 19 July, Other factors may be responsible for that LR variation differed from the relative humidity, such as aerosol type, especially aerosol size and virtual refractive index.

\subsection{Validation}

At present, we cannot test night AOD. However, our base has purchased Cimel's fully automatic multi-band photometer CE318T, which reflects the optical characteristics of the atmosphere by observing the reflections of the sun, sky, moon, and ground. It can be observed together during the day and night to provide all-day observations, providing aerosol data's quantitative and physical optical properties. In this way, after a period of operation, the night AOD calculated by MPL can be verified.

The AOD calculated from the MFR photometer observations at the same site were used to validate the accuracy of aerosol extinction coefficient retrieval based on ground visibility. All the data collected under cloudy conditions were excluded. The temporal resolution for MFR was 1 min, 


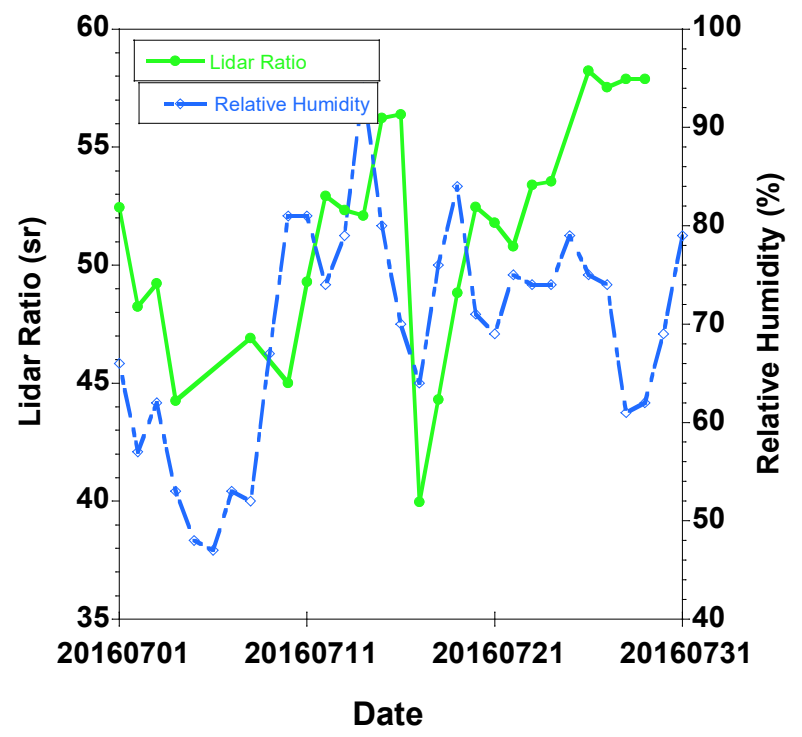

Fig. 3. Lidar ratio (sr) and relative humidity (\%) time series based on ground visibility of July, 2016.

whereas for MPL, it was $0.5 \mathrm{~min}$, processed to $1 \mathrm{~min}$ for comparison purposes. Because MFR can only retrieve AOD during daytime, the comparison was performed based on data collected in daytime under non-cloudy and non-rainy conditions.

Fig. 4(a) presents scatter plots of the AOD calculated from MFR and retrieved from MPL at a minute temporal resolution. The majority points were concentrated at AOD values of $0.15-0.5$, and only $0.0009 \%$ of points had values of $0.5-0.7$. The coefficients between MFR and MPL calculated AOD was $0.778(P=0.0001)$. As shown in Fig $4(b)$, the result of far-end Fernald solution is a bit less than near-end Fernald solution. Compared with MFR, AOD retrieved from MPL by the near-end Fernald solution is greater in the morning and in contrast, less in the afternoon. As shown in Fig. 4(c), in 0.1-0.2, there are more frequency of low AOD retrieved by MFR than by MPL. In 0.2-0.3, there are less frequency of high AOD retrieved by MFR than by MPL. Therefore, when AOD is low, the values that MPL retrieved are bigger than MFR's. When AOD is high, the values that MPL retrieved are smaller than MFR's.

The fair correlation coefficients of the retrieval were mainly the result of the following factors: 1. Visibility data uncertainty. The forward scattering visibility meter uses scattering from aerosol particles, and the relationship between the scattering signal at a certain angle and total

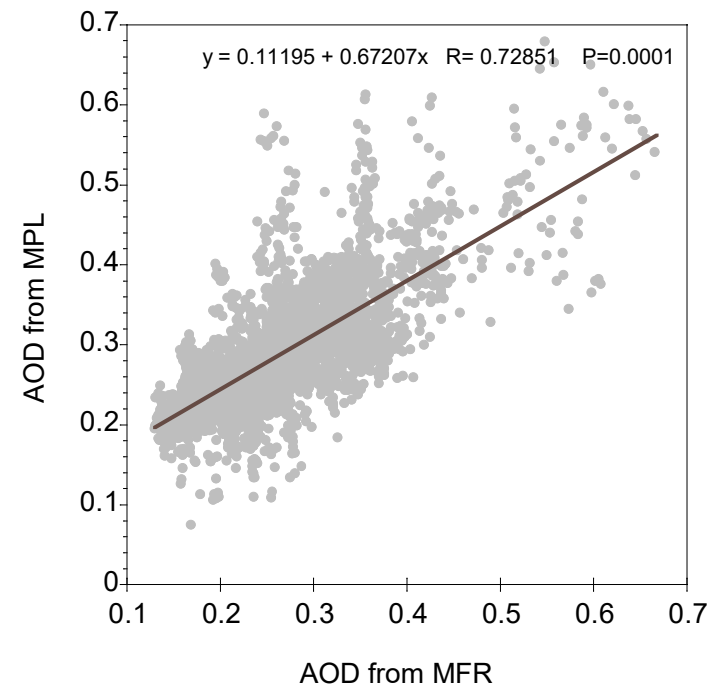

Fig. 4(a). Scatter plot for AOD calculated by MFR and MPL. 


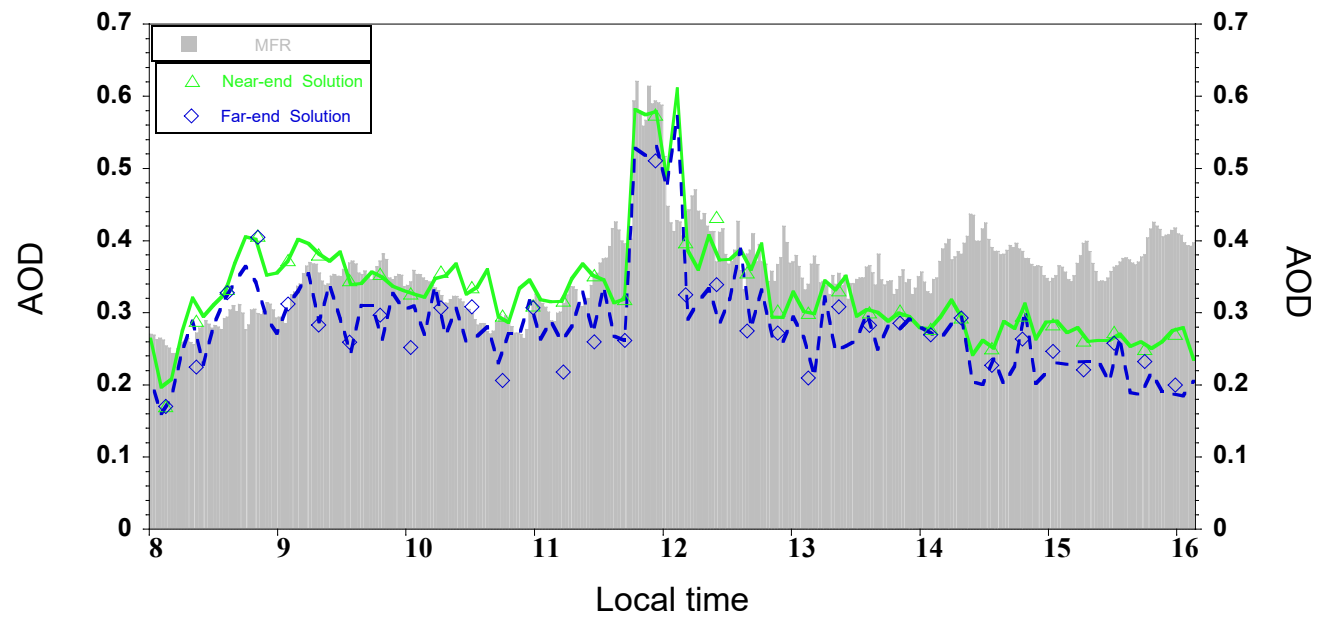

Fig. 4(b). Time series of AOD calculated by MFR and MPL on 23 July 2016.

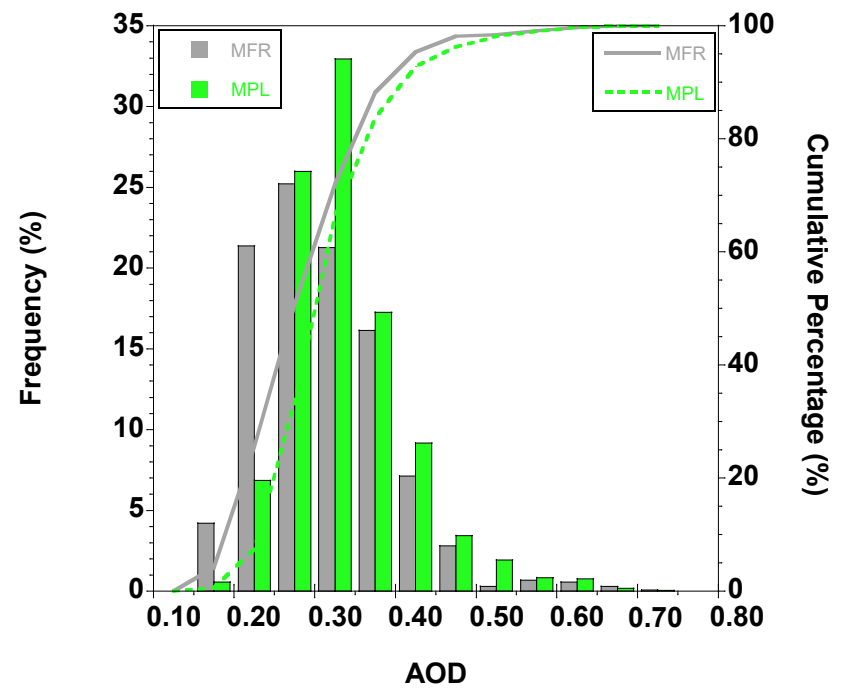

Fig. 4(c). Density plot of AOD calculated by MFR and MPL.

scattering value is used to determine visibility. This approach had intrinsic limitations. First, because of limited sampling volume, visibility measurements within a certain range are point values and cannot represent larger area values. Second, the main error sources of visibility are scattering phase function changes caused by aerosol properties. Because of uncertainty of aerosol properties, the relative uncertainty of visibility reaches $28 \%$ actually (Li et al., 2009).

2. Aerosol vertical distribution model within lidar blind zone. The lidar blind zone includes the near-surface layer within which meteorological variables have a larger vertical gradient than the free atmosphere. Furthermore, aerosol vertical distribution variability is large (Yang et al., 2005). Calculation under uniform distribution assumption induces biases.

\subsection{Vertical Distribution Characteristics}

Ground visibility was used to calibrate LR and CE to obtain the dynamic LR and the aerosol vertical distribution under cloudy sky conditions and at night. The current commonly used retrieval method is Fernald's (1984) far-end solution method; the boundary value is defined as the clean layer at the upper atmospheric layer with very low aerosol content, and the solar photometer observed $A O D$ is used to calculate the corresponding LR and pick the most reasonable one. Therefore, under cloudy sky conditions and at night, the solar photometer cannot observe AOD, and thus aerosol vertical distribution cannot be calculated. 
Fig. 5 presents the retrieved lidar extinction coefficient based on ground visibility for July. All data collected under rainy, cloudy, and foggy conditions were filtered out and statistical analyses were performed for 12:00 and 00:00 to represent daytime and nighttime aerosol vertical distribution features, respectively. Fig. 5 reveals that aerosol peaked at approximately $2000 \mathrm{~m}$ during daytime. Nighttime distribution displayed three characteristics: monotonically decreased from the ground to the upper layer, a peak at $600 \mathrm{~m}$, and two peaks at approximately $1200 \mathrm{~m}$. The aerosol extinction coefficient was higher at night than during the day below $2000 \mathrm{~m}$. The aerosol extinction coefficient was higher in the day than at night between 2000 and $2500 \mathrm{~m}$. The aerosol extinction coefficient was consistent during the day and night above $2500 \mathrm{~m}$.

Fig. 6 presents the time series for the aerosol extinction coefficient retrieved from dynamic LR, which is based on ground visibility on 23 July 2016. Both daytime (Fig. 6(a)) and nighttime (Fig. 6(b)) data is displayed. Aerosol concentration near the ground began to increase from 8:00 in the morning, reaching to the maximum value after 12:00; in the vertical direction, the high concentration aerosol area $\left(>0.24 \mathrm{~km}^{-1}\right)$ was below $1000 \mathrm{~m}$, the low concentration aerosol area $\left(<0.054 \mathrm{~km}^{-1}\right)$ extended to as high as $5000 \mathrm{~m}$ during 11:00-14:00. The aerosol concentration in the lower layer began to decrease at 20:00 and reached the minimum value after 4:30; in the vertical direction, the high concentration aerosol area $\left(>0.24 \mathrm{~km}^{-1}\right)$ at night was much smaller than in the day. Fig. 5(b) also reveals that there were rainy clouds at $4000 \mathrm{~m}$ at 3:00-6:00 and there should have been light rain on the ground. Although records for 3:00-4:00 were unavailable, a $0.6 \mathrm{~mm} \mathrm{~h}^{-1}$ rain rate was measured at 5:00-6:00.

\section{CONCLUSIONS}

The advantage of using ground visibility to retrieve aerosol vertical extinction coefficient is

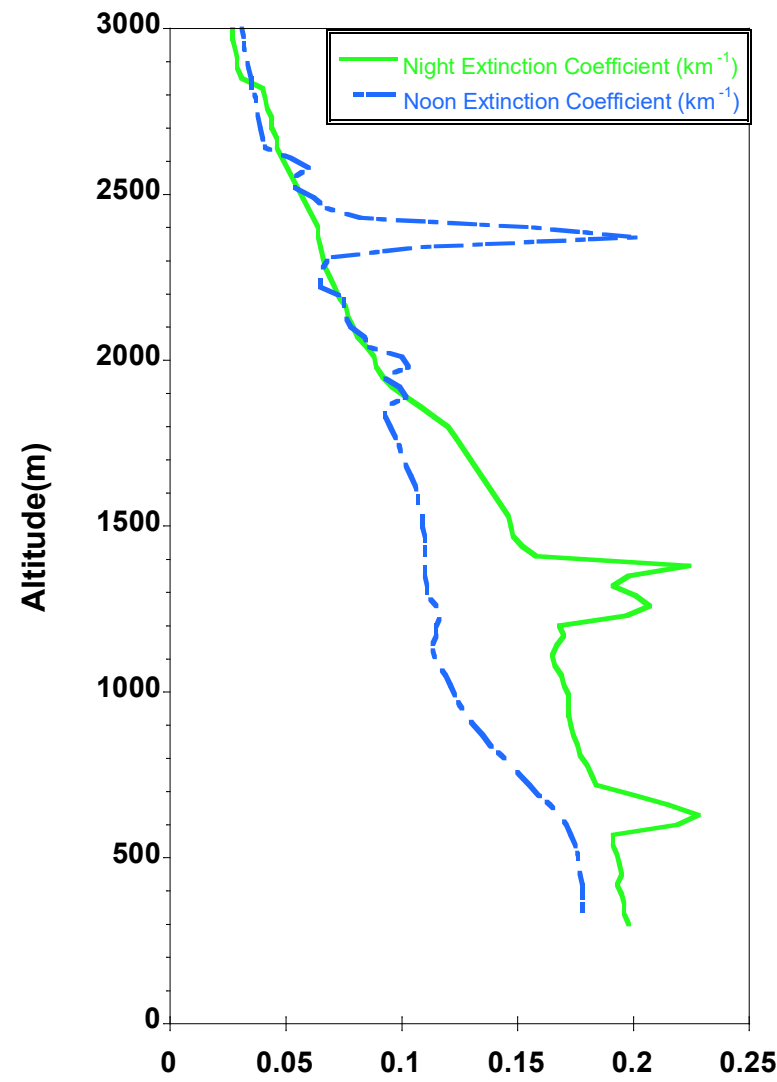

Day and Night Extinction Coefficient $\left(\mathrm{km}^{-1}\right)$

Fig. 5. Monthly average aerosol extinction coefficient vertical distribution at 12:00 and 24:00 local time $(U T C+8)$ for July in Xi'an. 


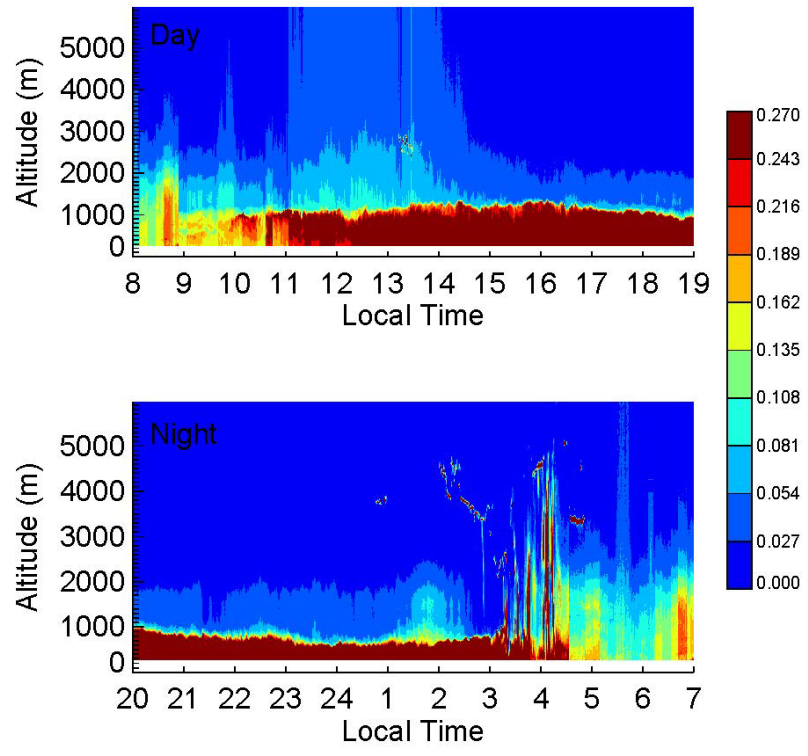

Fig. 6. Aerosol extinction coefficient vertical distribution for day (upper panel) and night (lower panel) on 23 July 2016.

twofold. First, this method can be used to calculate dynamic LR and improve retrieval accuracy. Second, calibration height and boundary value cannot be determined reasonably under cloudy conditions and at night, which is circumvented by the present method. On the basis of the linear relationship between the lidar near-end signal and ground aerosol extinction coefficient, Fernald's lidar equation can be used to obtain near-end solution and retrieve the aerosol vertical extinction coefficient. The main results are as follows:

1. When matching up the visibility and lidar echo data every minute, the near-end lidar signal (photons) and aerosol extinction coefficient were highly correlated $\left(R^{2}=0.9659, P=0.0001\right)$. The intercept and slope of the linear regression between the two variables are $C E$ and dynamic LR.

2. The dynamic LR can be used to retrieve the AOD. The results revealed that the majority of AOD values fall within $0.15-0.5$ during summer at Xi'an, and only $0.009 \%$ of all the points have a value of $0.5-0.7$. The values are close to those from the MFR photometer observed AOD at the same wavelength of $532 \mathrm{~nm}$ with a correlation coefficient of 0.77 .

3. The aerosol vertical distribution displayed different characteristics in daytime and nighttime during summer. One peak appeared at approximately $2000 \mathrm{~m}$ was observed in the day. More complicated structures were observed at night; first, a monotonical decrease from the ground to the upper layer was observed, followed by a peak at approximately $600 \mathrm{~m}$, and finally, a double peak at approximately $1300 \mathrm{~m}$. In general, the aerosol extinction coefficient at night is higher than during the day below $1200 \mathrm{~m}$, with higher values at night than in the day being closer to the ground.

\section{ACKNOWLEDGMENTS}

We are grateful for the two reviewers' helpful comments and suggestions, which improved the manuscript. This work was supported by the Basic Research Plan of Natural Science in Shaanxi Province 2017JM4010. This manuscript was edited by Wallace Academic Editing.

\section{REFERENCES}

Ackermann, J. (1998). The extinction-to-backscatter ratio of tropospheric aerosol: A numerical study. J. Atmos. Oceanic Technol. 15, 1043-1050. https://doi.org/10.1175/1520-0426(1998)0 15<1043:TETBRO>2.0.CO;2 
Campbell, J.R., Hlavka, D.L., Welton, E.J., Flynn, C.J., Turner, D.D., Spinhirne, J.D., Scott, V.S., Hwang, I.H. (2002). Full-time, eye-safe cloud and aerosol lidar observation at Atmosphere Radiation Measurement program sites: Instrument and data processing. J. Atmos. Oceanic Technol. 19, 431-442. https://doi.org/10.1175/1520-0426(2002)019<0431:FTESCA>2.0.CO;2

Chen, T., Wu, D., Liu, B., Cao, K., Wang, Z., Bo, G., Yuan, L., Zhou, J. (2010). A new method for determining aerosol backscatter coefficient boundary value in the lower troposphere. Acta Optica Sin. 30, 1531-1536. https://doi.org/10.3788/AOS20103006.1531 (in Chinese)

Collis, R.T.H., Russell, P.B. (1976). Lidar measurement of particles and gases by elastic backscattering and differential absorption, in: Hinkley, E.D. (Ed.), Laser Monitoring of the Atmosphere, Springer, Berlin, Heidelberg, pp. 71-151. https://doi.org/10.1007/3-540-07743X_18

Doherty, S.J., Anderson, T.L., Charlson, R.J. (1999). Measurement of the lidar ratio for atmospheric aerosols with a $180^{\circ}$ backscatter nephelometer. Appl. Opt. 38, 1823-1832. https://doi.org/10. 1364/AO.38.001823

Fernald, F.G. (1984). Analysis of atmospheric lidar observations: Some comments. Appl. Opt. 23, 652-653. https://doi.org/10.1364/AO.23.000652

Klett, J.D. (1981). Stable analytical inversion solution for processing lidar returns. Appl. Opt. 20, 211-220. https://doi.org/10.1364/AO.20.000211

Li, C., Liu, Q., Mao, J., Chen, A. (2004). An aerosol pollution episode in Hong Kong with remote sensing products of Modis and Lidar. J. Appl. Meteorol. Sci. 15, 641-650. (in Chinese)

Li, H., Sun X.J. (2009). Theoretical analysis on measurement error of forward scattering visibility meter. Infrared Laser Eng. 6, 1094-1098. https://doi.org/10.3969/j.issn.1007-2276.2009.06.031 (in Chinese)

Lin, C., Yang, D., Li, C., Li, Q., Shi, G. (2013). A micro-pulse lidar observation of aerosol in Beijing and retrieval algorithm research. Acta Peking Univ. Nat. Sci. 49, 426-434. http://xbna.pku.edu. cn/CN/Y2013/V49/13/426 (in Chinese)

Liu, H., Ge, Z., Wang, Z., Huang, W., Zhou, J. (2008). Extinction coefficient inversion of airborne Lidar detecting in low-altitude by Fernald iterative backwark integration method (FIBIM). Acta Optica Sin. 28, 1837-1843. https://doi.org/10.3321/j.issn:0253-2239.2008.10.001 (in Chinese)

Omar, A.H., Liu, Z., Vaughan, M.A. (2010). Extinction-to-backscatter ratios of Saharan dust layers derived from in situ measurements and CALIPSO overflights during NAMMA. J. Geophys. Res. 115, 9-12. https://doi.org/10.1029/2010JD014223

Otto, S., Bierwirth, E., Weinzierl, B., Kandler, K., Esselborn, M., Tesche, M., Schladitz, A., Wendisch, M., Trautmann, T. (2009). Solar radiative effects of a Saharan dust plume observed during SAMUM assuming spheroidal model particles. Tellus B 61, 270-296. https://doi.org/10.1111/j. 1600-0889.2008.00389.x

Pietruczuk, A., Podgórski, J. (2009). The lidar ratio derived from sun-photometer measurements at Belsk Geophysical Observatory. Acta Geophys. 57, 476-493. https://doi.org/10.2478/s1160 0-009-0006-9

Schuster, G.L., Vaughan, M., MacDonnell, D., Su, W., Winker, D., Dubovik, O., Lapyonok, T., Trepte, C. (2012). Comparison of CALIPSO aerosol optical depth retrievals to AERONET measurements, and a climatology for the lidar ratio of dust. Atmos. Chem. Phys. 12, 74317452. https://doi.org/10.5194/acp-12-7431-2012

Spinhirne, J.D. (1993). Micro pulse lidar. T. Geosci. Remote. 31, 48-55. https://doi.org/10.1109/3 6.210443

Srivastava, A.K., Tripathi, S.N., Dey, S., Kanawade, V.P., Tiwari, S. (2012). Inferring aerosol types over the Indo-Gangetic Basin from ground based sunphotometer measurements. Atmos. Res. 109-110, 64-75. https://doi.org/10.1016/j.atmosres.2012.02.010

Wang, X., Rao, R. (2005). Lidar ratios for atmospheric aerosol and cloud particles. Chin. J. Lasers 32, 1321-1324. https://doi.org/10.3321/j.issn:0258-7025.2005.10.005 (in Chinese)

Xue, Z., Zhang, L., Zuo, X., Huang, Y., Shen, Y., Sun, J. (2016). Comparative evaluation of visibility on manual and automatic observation of visibility in Ningxia. Mete. Hydrolog. Mar. Instrum. 33, 100-104. https://doi.org/10.19441/j.cnki.issn1006-009x.2016.03.022 (in Chinese)

Yang, L., He, K., Zhang, Q., Wang, Q. (2005). Vertical distributive characters of $\mathrm{PM}_{2.5}$ at the ground layer in autumn and winter in Beijing. Res. Environ. Sci. 18, 23-28. https://doi.org/10.1007/s1 0971-005-6694-y 
Yao, T., Huang, X., He, L., Hu, M., Sun, T. (2010). High time resolution observation and statistical analysis of atmospheric light extinction properties and the chemical speciation of fine particulates. Sci. China Chem. 8, 206-214. https://doi.org/10.1007/s11426-010-4006-z

Zhou, J., Yue, G., Qi, F., Jin, C. (1998). Opitcal properties of aerosol derived from Lidar measurements. Chin. J. Quantum Elect. 15, 140-148. (in Chinese) 